\title{
An Interactive Software Package for the Investigation of Hydrodynamic-Slider Bearing-Lubrication
}

\author{
A. ALPER OZALP, ${ }^{1}$ S. AYSE OZEL ${ }^{2}$ \\ ${ }^{1}$ Uludag University, Department of Mechanical Engineering, 16059 Gorukle, Bursa, Turkey \\ ${ }^{2}$ Bilkent University, Department of Computer Engineering, 06533 Bilkent, Ankara, Turkey
}

Received 15 May 2003; accepted 7 July 2003

\begin{abstract}
The temperature dependent character of viscosity complicates the numerical analysis of hydrodynamic slider bearings and the geometry of the flow cavity plays a significant role on the design and performance of the lubrication systems. In this paper, we represent a recent software tool, named as "HYDRO-LUB," capable of performing constant and variable viscosity runs in various pad styles with moving boundaries. Results of the demonstrating project are not only consistent with the available literature but also show the fast and reliable character of the package; which in return put forward the advantages of applying the program in the lubrication courses of mechanical engineering. ( ) 2003 Wiley Periodicals, Inc. Comput Appl Eng Educ 11: 103-115, 2003; Published online in Wiley InterScience (www.interscience.wiley.com.); DOI 10.1002/ cae.10047
\end{abstract}

Keywords: interactive software package; temperature dependent viscosity; slider bearing

\section{INTRODUCTION}

With the recent improvements in computer science, progress in many branches of technology and education is dependent on the development of new

Correspondence to A. A. Ozalp (aozalp@uludag.edu.tr).

(C) 2003 Wiley Periodicals Inc. software tools, as described by Ozalp [1] and Sanz et al. [2], that are specialist in the fundamental aspects of design processes. Especially when the concept is to dispatch mechanical energy, power, friction, and even wear stand in the background as the major parameters to be considered. Slider bearings are widely used in the transmission systems of many engineering applications like mechanical seals, machine tool ways, piston rings, and plain collar thrust bearings, for their 
load-carrying capacity, excellent stability, and durability. Computer aided analysis of slider bearing lubrication is sufficiently complex due to the need for the simultaneous solution of momentum and energy equations; but the temperature dependent character of viscosity can make it more complicated, especially when the streamwise decay of lubricant viscosity comes out to be significant on the overall performance.

In spite of the importance of the temperature dependency of viscosity, in a considerable number of recent theoretical studies viscosity was considered to be constant and isotropic studies were performed. Hargreaves and Elgezawy [3] experimentally and numerically investigated a transverse groove machined in a flat slider pad, which had an outlet film thickness of $0.5 \mathrm{~mm}$ and used a low viscosity lubricant of SAE 20 and Das [4] numerically investigated inclined and parabolic slider bearings with nonNewtonian oils. While Nabhan et al. [5] used the Newton-Raphson iterative technique on the binary water-based lubricant flow, Lin [6] tried to get an optimum flow cavity for one-dimensional porous curved slider bearing.

To focus on the effects of temperature and lubricant properties on the performance of slider bearings, there have been many studies that carried out iterative methods to take the streamwise variation of oil viscosity into account. Roles of temperature and pressure on viscosity, shear stress, and density values and on the formation of lubricant film, for a number of lubricants, were experimentally investigated by Hoglund [7]. Fang et al. [8] presented a new numerical method in which the effects of pressure and temperature on the rheological properties of lubricants, on the elastic shear modulus, and on shear stress values of the lubrication volume were considered. A linearly narrowing slider bearing, with heat conduction to the stationary lower surface was investigated numerically by Kumar et al. [9] and similar studies were performed by Pandey and Ghosh [10], Ghosh and Gupta [11], Yoo and Kim [12] on both sliding and rolling contacts.

The cavity used in the hydrodynamic lubrication of plane slider bearings can be described by four parameters; the bearing length (L), bearing inlet and exit heights $\left(\mathrm{h}_{\mathrm{in}}, \mathrm{h}_{\mathrm{ex}}\right)$, and the geometric style, which defines the way of height variation throughout the flow strip (Fig. 1(a)). The film action of the lubricant comes both from the pumping of the oil into the flow volume and from the behavior of two lubricated surfaces. For one-dimensional, incompressible, and Newtonian type lubricant flows, Reynolds' method [13], which neglects the inertial forces and concentrates on the viscous shear and pressure forces, appears to be convenient to use for the theoretical approach. Since the load carrying capacity of the bearings is one of the major interest areas of research, it was custom to assume either a linear (Fig. 1(b)) or a quadratic (Fig. 1(c)) pressure distribution to facilitate the complex numerical investigations [13]. On the other hand, the energy transfer within the pad is of high importance; not only from the point of system performance and damage but also being an account for power loss and having a thermodynamic relationship with the temperature dependent character of viscosity. Although the system is one-dimensional, handling the continuity, momentum, and energy equations simultaneously and taking the streamwise decay of lubricant viscosity into consideration turns out to be a demanding and complex work.

For the above mentioned reasons and to provide a visual design/analysis/educational tool for stationary and sliding bearing operations of one dimensional, incompressible, constant (isotropic approach), and variable (iterative approach) oil viscosity flows in variable height plane slider bearings, a PC based computer program named "HYDRO-LUB" has been

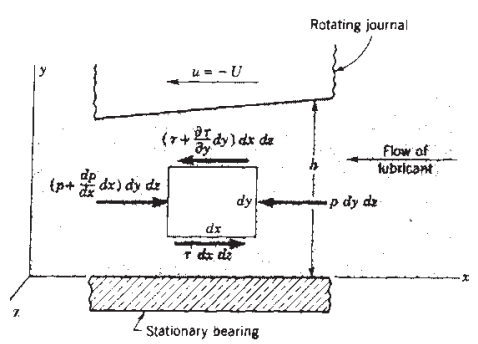

(a)

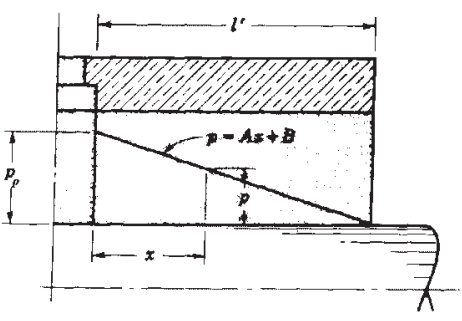

(b)

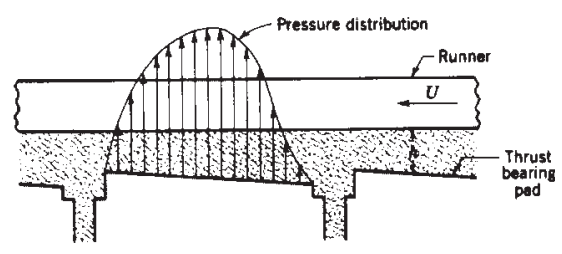

(c)

Figure 1 (a): Pressure and shear forces acting on the infinitesimal oil element, (b)-(c) linear and second order oil-pressure distribution on simple bearing geometries [13]. 
developed. The package is capable of performing not only isotropic analysis, where the oil viscosity is regarded to be constant throughout the flow, but also iterative runs for decreasing oil viscosity, being a function of temperature, in the flow direction. As the variation of flow parameters (temperature, velocity, pressure etc.) can be determined in the isotropic cases, iterative operations cover both the isotropic regime skills and the determination of the temperature dependency of any flow property, mainly the viscosity, and the complete flow knowledge. Besides computing the flow properties, the main aim is to study the effects of different bearing geometries, oil types, and thermodynamic inputs on the flow pattern and on results, by which the design of actual systems can be supported.

\section{GOVERNING EQUATIONS}

The Reynolds' approach [13] to plane slider bearings is mainly based on the one-dimensionality of oil flow, incompressibility of oil, and the viscous behavior being of Newtonian type. In the calculation procedure; density $(\rho)$ and specific heat under constant pressure $\left(\mathrm{C}_{\mathrm{p}}\right)$ values of the lubrication oil are regarded to be constant and height of the oil film (h), lower and upper surface velocities $\left(\mathrm{V}_{\mathrm{l}}, \mathrm{V}_{\mathrm{u}}\right)$ seem to be the major variables of the plane slider bearing. Since the inertial forces are neglected and assuming that the bearing extends infinitely in the z-direction (Fig. 1(a)), the momentum equation in the flow direction simplifies to Equation 1(a). This equation displays the relation of pressure $(\mathrm{P})$ variation in the streamwise direction $(\mathrm{x}-)$ and oil velocity (u) variation in the longitudinal direction (y-). On the other hand, volumetric flow rate per unit depth $\left(\mathrm{q}_{\mathrm{x}}\right)$ is calculated by Equation 1(b), in fact Equations 1(b) - (c) appear by the implementation of the boundary conditions and are the open and differential forms of Equation 1(a), respectively. As the temperature $(\mathrm{T})$ variation is dealt by the energy equation (Eq. 2(a)), the friction force $\left(\mathrm{F}_{\mathrm{f}}\right)$ is calculated by the integration of shear stress $(\tau)$ variation on the slider surface (Eq. 2(b) -(c)) [13,14].

$$
\begin{aligned}
\frac{\mathrm{dP}}{\mathrm{dx}}=\mu \frac{\mathrm{d}^{2} \mathrm{u}}{\mathrm{d}^{2} \mathrm{y}} \quad \mathrm{q}_{\mathrm{x}} & =-\frac{\mathrm{h}^{3}}{12 \mu} \frac{\mathrm{dp}}{\mathrm{dx}}+\frac{\left(\mathrm{V}_{1}+\mathrm{V}_{\mathrm{u}}\right) \mathrm{h}}{2} \\
\frac{\mathrm{d}}{\mathrm{dx}}\left(\frac{\mathrm{h}^{3}}{\mu} \frac{\mathrm{dP}}{\mathrm{dx}}\right) & =6\left(\mathrm{~V}_{1}+\mathrm{V}_{\mathrm{u}}\right) \frac{\mathrm{dh}}{\mathrm{dx}} \\
\rho \mathrm{C}_{\mathrm{p}}\left(q_{\mathrm{x}} \frac{\mathrm{dT}}{\mathrm{dx}}\right)= & \frac{\mu\left(\mathrm{V}_{1}+\mathrm{V}_{\mathrm{u}}\right)^{2}}{\mathrm{~h}}+\frac{\mathrm{h}^{3}}{12 \mu}\left(\frac{\mathrm{dP}}{\mathrm{dx}}\right)^{2} \\
\tau & =\mu \frac{\mathrm{du}}{\mathrm{dy}} \mathrm{F}_{\mathrm{y}=0} \quad \mathrm{~F}_{\mathrm{f}}=\int \tau \mathrm{dx}
\end{aligned}
$$

Load (W) carried by the bearing and the friction coefficient (f) are calculated by Equations 3(a)-(b), respectively. Vogel's rule (Eq. 3(c)) [14] fits the Newtonian viscosity $(\mu)$-temperature relation in the best way, where $\mathrm{b}, \mathrm{k}$, and $\theta$ are the viscosity parameters. As the pumping power $\left(\Omega_{\mathrm{p}}\right)$ necessary to supply the lubrication oil is defined by Equation 3(d), the power loss $\left(\Omega_{\mathrm{lo}}\right)$ due to the temperature increase of oil (or due to friction) is computed by Equation 3(e) [13].

$$
\begin{gathered}
\mathrm{W}=\int \mathrm{Pdx} \quad \mathrm{f}=\frac{\mathrm{F}_{\mathrm{f}}}{\mathrm{W}} \quad \mu=\rho \mathrm{ke}^{\frac{\mathrm{b}}{\mathrm{T}+\theta}} \\
\Omega_{\mathrm{p}}=\mathrm{q}_{\mathrm{x}} \mathrm{P}_{\mathrm{p}} \quad \Omega_{\mathrm{lo}}=\rho \mathrm{q}_{\mathrm{x}} \mathrm{C}_{\mathrm{p}} \Delta \mathrm{T}
\end{gathered}
$$

\section{SOFTWARE PACKAGE “HYDRO-LUB”}

The interactive software package "HYDRO-LUB" is written in Visual Basic 6.0 professional language [15] and should be supported by a high resolution colour monitor to benefit from the colourful user interfaces and graphical outputs. A PII processor PC is essential due to the extensive calculations, especially for cases where temperature dependent character of viscosity complicates the analysis, within the solution procedure.

File operations, configuration of the system layout, project solver, and graphical outputs are the four main modules of the package, and they are displayed in the hierarchical structure (Fig. 2). The main menu is to appear first upon start-up and displays certain main and sub entries (Fig. 3(a)) together with the shortcut command buttons that are arranged in the operation order on the process toolbar (Fig. 3(b)). Throughout the package, clicking either the relevant menu entry or the corresponding command button carries out different operations.

File operations are coordinated by the first module; using the sub entries of the "File" entry,

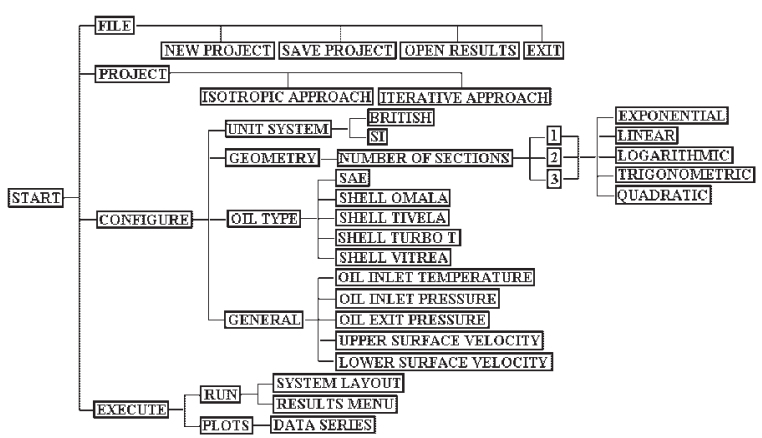

Figure 2 Hierarchical structure of "HYDRO-LUB." 


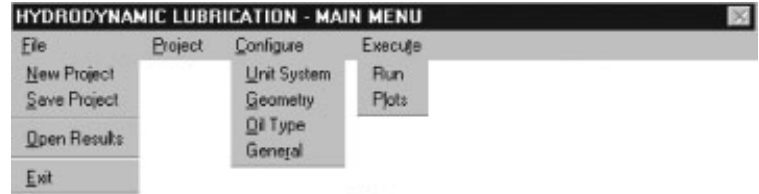

(a)

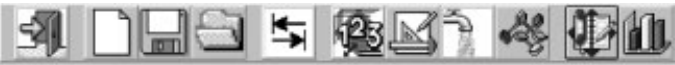

(b)

Figure 3 (a) Main menu, (b) toolbar.

"New Project," "Save Project," "Open Results," and "Exit" activities can be performed. The second module, charged with the configuration of "SYSTEM LAYOUT," operates through the sub entries of the "Configure" entry. During configuration, available options are displayed on frames and the desired one is selected by clicking the relevant option box. Calculations can be carried out either in British or SI unit system (Fig. 4(a)), geometry definition of the bearing covers not only the input of the inlet height, exit height, and the length, but also the style of height variation. Exponential, linear, logarithmic, quadratic, and trigonometric styles are prepared to represent the variation and a single bearing can be defined by the consecutive-connections up to three of these choices. As the upper part of the "CONFIGURE-GEOMETRY" menu shows the input frame, lower part displays the formulation constants and the outline of the bearing (Fig. 4(b)). Oil type is selected from a set of 32 alternatives using the "CONFIGURE-OIL TYPE" menu. Clicking the relevant option box displays certain properties on the screen (Fig. 4(c)). Inlet and exit oil pressures, upper and lower surface velocities, and inlet oil temperature values are supplied to the program through the "CONFIGUREGENERAL" menu (Fig. 4(d)).

Third module is responsible for the project solver. To select the project type, either the "Project" entry or the relevant shortcut command button should be clicked. The first analysis type (Fig. 4(e)) considers the oil viscosity to be constant throughout the bearing, whereas the second takes into account the variation of viscosity with temperature. Either of the projects starts through the "Run" sub-entry and ends with the appearance of two new menus, one displaying the "SYSTEM LAYOUT" (Fig. 5(a)), with all the input data supplied in the configuration module, the other containing the output frames of the selected project type. As the upper frame of the "RESULTS MENU"
(Figs. 5(b)-(c)) is prepared for the primary outputs like bearing load, friction force and coefficient, and temperature increase, the lower frame contains the nodal results. A mapping operation, throughout the bearing length is executed; $1000 \mathrm{x}$-locations, following each other with equal increments, are investigated and 12 parameters, for each location, like pressure, viscosity, temperature, pressure gradient, oil velocity, impulse, shear stress, etc. are stored in an array.

The fourth module, graphical outputs, is not enabled until a project is completed successfully. The above mentioned calculated and stored parameters are the source of plot applications. One of the main goals of "HYDRO-LUB" is the possibility of plotting the variation of any parameter versus another. Since the working ranges are divided into 1000 equally spaced intervals, highly sensitive plots are available. Parameter selection frame (Fig. 6), containing all the calculated parameters, can be accessed through the "Plots" sub-entry of the main menu.

Configuration of the physical flow environment and the thermodynamic and the fluid mechanics based input procedure must be completed by the users without wrong or unlogical values and in the abovedefined sequence. To prevent user errors and to guide students/engineers, a special sub-program, named as "Execution Controller" [1], runs simultaneously with the four main modules. "Execution Controller" informs the user not only about the errors but also about the current state of a continuing project by certain messages, as given in Figures 7(a)-(d). The main goal of "Execution Controller" is that the user does not have to run it specifically or check a debug window type environment at any stage of a project but will get information of any kind at the configuration/ input/run phases of "HYDRO-LUB."

\section{DEMONSTRATING PROJECT}

To put forth the computational and graphical utilities of the program and to show the effects of viscosity and geometric design of the flow volume, an example project is presented in this section. To produce a comprehensive overview, calculations are performed with three different lubricants at two different inlet temperatures for 10 different bearing lengths and 10 different exit heights. Results of the isotropic and iterative methods are discussed by means of the recent numerical studies and compared through lubricant flowrates, velocity profiles, streamwise pressure and temperature variations, friction force, load capacity, and power consumption values of the bearing. 


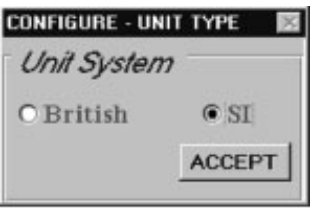

(a)

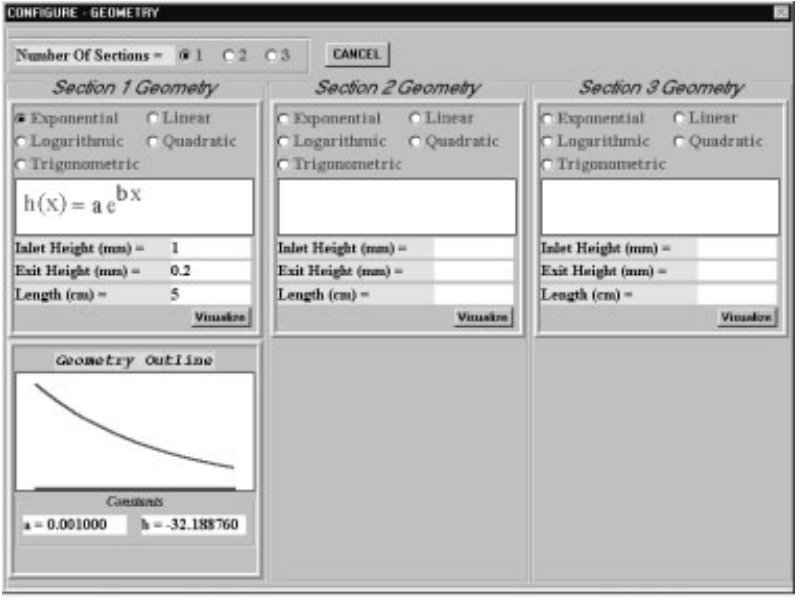

(b)

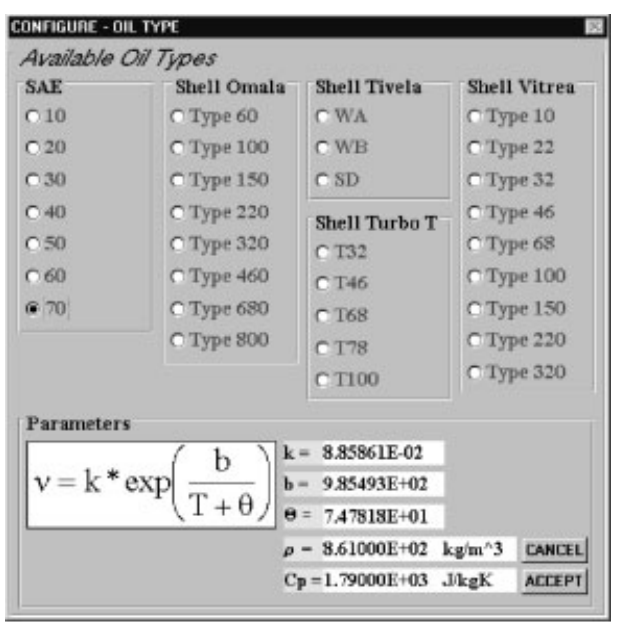

(c)

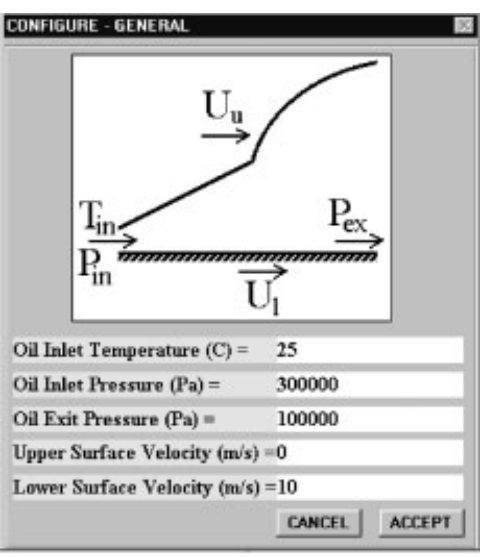

(d)

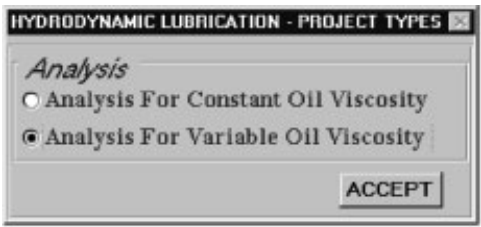

(e)

Figure 4 Configuration menus of "HYDRO-LUB" (a) Unit system, (b) Geometry, (c) Oil type, (d) General, (e) Project type.

\section{Theoretical Model}

Definition of the theoretical model consists of the knowledge about the physical domain, velocities of the upper and lower surfaces of the bearing, inlet and exit boundary conditions regarding the thermodynamic, and fluid mechanics data and the lubricant type. To emphasize the relevance of the present software package, the necessary compounds, that are convenient to assemble, are chosen from the recent numerical studies and the input procedure is carried out through the configuration menus of Figure 4. The general scheme of the slider bearing is similar to that of Lin [6], narrowing in exponential nature (Fig. 4(b)), and given in Figure 8. Upper surface of the bearing is kept stationary $\left(V_{u}=0 \mathrm{~m} / \mathrm{s}\right)$, which is the case not 


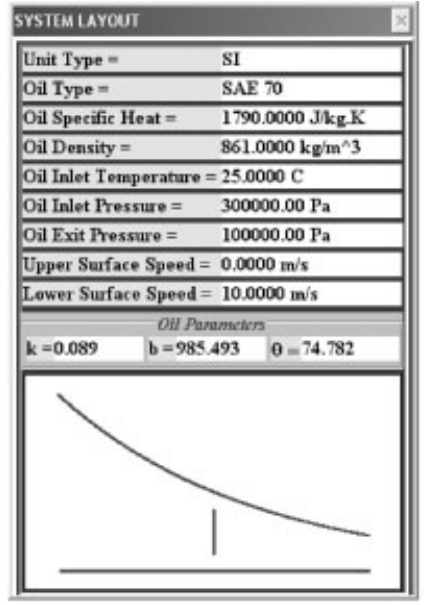

(a)

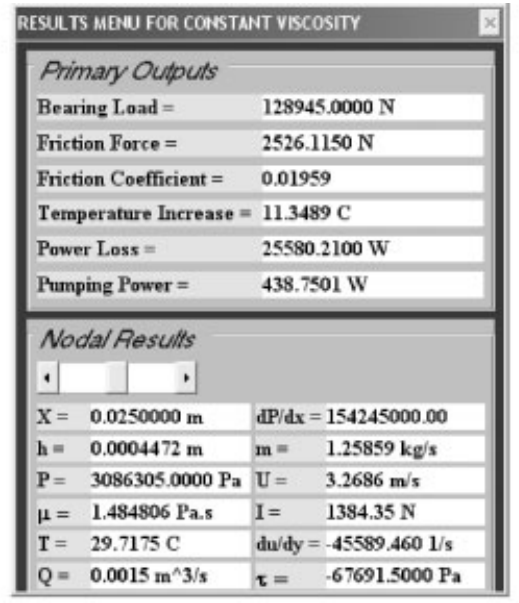

(b)

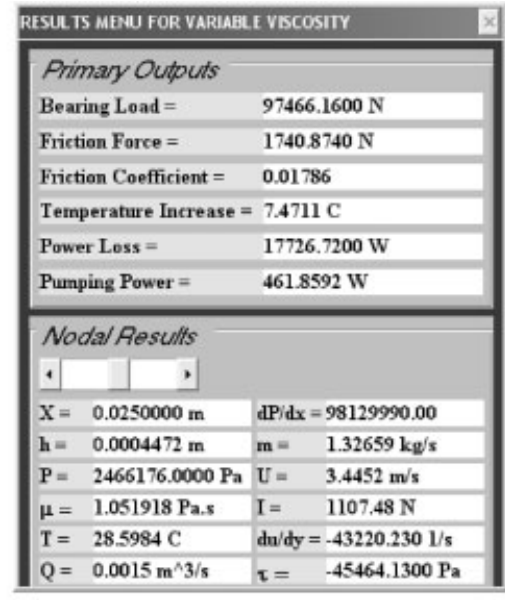

(c)

Figure 5 (a) "SYSTEM LAYOUT", (b)-(c) "RESULTS MENU" s of isotropic (constant viscosity) and iterative (variable viscosity) analysis.

only in the study of Nabhan et al. [5] but also in most of the industrial applications. Whereas lower surface velocity is decided to be $10 \mathrm{~m} / \mathrm{s}$ (Fig. 4(d)), which is not only a proper value for slider bearings [12] but is also equal to the circumferential velocity of a $50 \mathrm{~mm}$ diameter shaft having a rotational speed of $1910 \mathrm{rpm}$. To visualize the effects of viscosity variations in various flow geometries, 10 different inlet/exit height ratios, as in Das' [4] work, and 10 different bearing lengths are taken into consideration. As the base dimensions of the model are equated to that of Lin [6] with $\mathrm{L}_{\mathrm{b}}=1 \mathrm{~cm}$ and $\left(\mathrm{h}_{\mathrm{in}}\right)_{\mathrm{b}}=1 \mathrm{~mm}$, the bearing length range is determined as $1-10 \mathrm{~cm}$ [9] and the exit height $\left(h_{e x}\right)$ range is selected as $1-0.1 \mathrm{~mm}$ with $1 \mathrm{~cm}$ and $0.1 \mathrm{~mm}$ increments, respectively.

\begin{tabular}{|l|l|}
\hline Data Series & \\
X-Axis & Y-Axis \\
O X-Location & X-Location \\
O Height & O Height \\
O Pressure & O Pressure \\
O Dynamic Viscosity & O Dynamic Viscosity \\
O Temperature & O Temperature \\
O Volumetric Flow Rate & O Volumetric Flow Rate \\
O Pressure Gradient & O Pressure Gradient \\
O Impulse & O Impulse \\
O Mass Flow Rate & O Mass Flow Rate \\
O du/dy at y=0 & O du/dy at $y=0$ \\
O Shear Stress & O Shear Stress \\
O Velocity & O Velocity \\
\hline
\end{tabular}

Figure 6 Parameter selection frame for plot applications.
Since different lubricant types play a notable role [7] on bearing performance, it is general practice to take up more than one lubricant [10]; thus, in order to form a general overview, in this work simulations are performed for three lubricants: SAE 30, SAE 50, and SAE 70 (Fig. 4(c)). The analysis is based on the fact that unused lubricant is pumped in and emerges to atmosphere, therefore inlet and exit oil pressure values are decided to be $300 \mathrm{kPa}$ and $100 \mathrm{kPa}$, respectively. Divers inlet oil temperatures are frequently coincided within the literature ([8-12]), to encompass the most recurrent ones into interest the research scope is widened with two oil inlet temperatures: $25^{\circ} \mathrm{C}$ (Fig. 4(d)) and $75^{\circ} \mathrm{C}$.

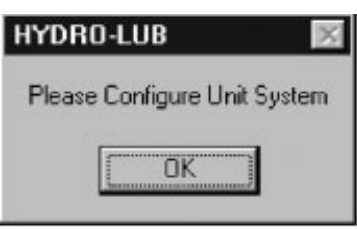

(a)

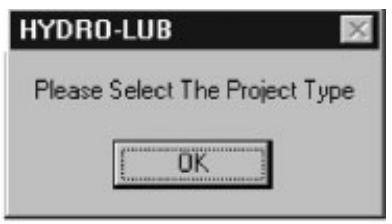

(b)

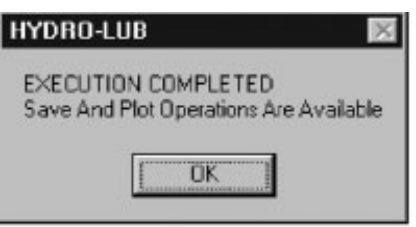

(c)

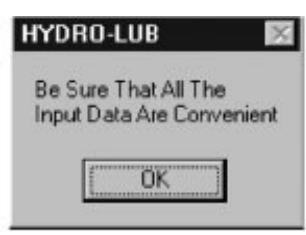

(d)
Figure 7 "Execution Controller" messages. 


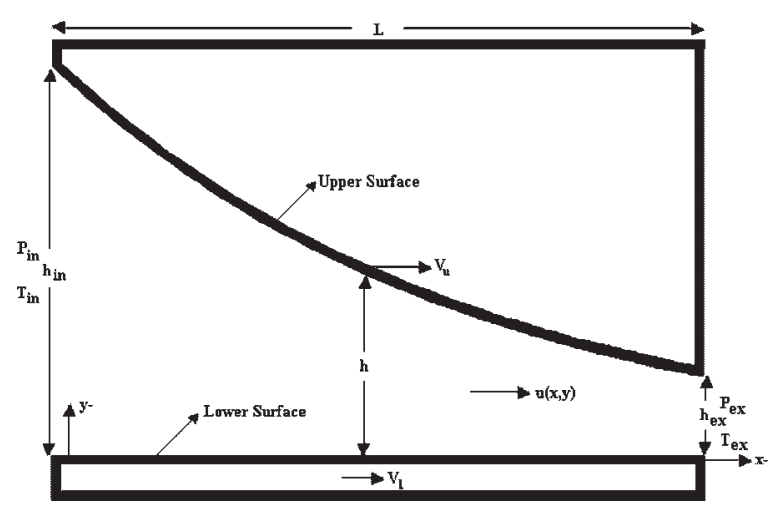

Figure 8 Schematic layout of slider bearing with curved upper surface.

\section{Results and Discussion}

The isotropic approach and the iterative method are applied to the slider bearing of Figure 8 with the above-defined boundary conditions for three different lubricants of SAE 30, 50, and 70 and the streamwise (x-) property variations are discussed in Figures 9 and 10 for the bearing with $\mathrm{h}_{\mathrm{in}}=1 \mathrm{~mm}, \mathrm{~h}_{\mathrm{ex}}=0.2 \mathrm{~mm}$, and $\mathrm{L}=5 \mathrm{~cm}$. As the lubricant flow rate must be constant in the streamwise direction, validity of both methods can be checked through its variation. In Figure 9(a) mass flow rate variations, calculated by the isotropic and iterative methods, are plotted for the lubricant of SAE 70, where the isotropic approach involves $\pm 0.05 \%$ deviation $(1.2583-1.2595 \mathrm{~kg} / \mathrm{ms})$ and that of the iterative is $\pm 0.06 \%(1.3252-1.3269 \mathrm{~kg} /$ $\mathrm{ms})$. The average flow rate value of the iterative method is higher than the average of the isotropic case by $5.07 \%$, which is an indicator of lower viscosity values, due to the temperature rise, thus lower resistive friction force. The iterative mass flow rates for SAE 30 and SAE 50 are also above the isotropic results by 1.1 and $2.92 \%$, respectively, which denote that results of the isotropic approach with thinner lubricants involve minor errors than those of more viscous cases.

Velocity profiles both for the isotropic and iterative runs, with the lubricants of SAE 30 and SAE 70, are given for the streamwise locations of $\mathrm{x}=0,0.01$, 0.02, 0.03, 0.04, 0.045, and $0.05 \mathrm{~m}$ in Figure 9(b). Either of the methods brought up back flow (bf) condition in the upstream regions of the bearing, where the end of the back flow region shifts downstream with more viscous lubricants, both in the isotropic and iterative methods, as denoted in Figure 10(a). As the upper boundary of back flow comes out to be in the region $\mathrm{x}=0.024-0.0256 \mathrm{~m}$ from the inlet, the deviation of the methods, from the point of back flow completion, is more apparent with SAE $70\left(\Delta \mathrm{x}_{\mathrm{bf}}=1.65 \mathrm{~mm}\right)$ and nearly vanishes with SAE $30\left(\Delta \mathrm{x}_{\mathrm{bf}}=0.4 \mathrm{~mm}\right)$. Moreover, the fluctuations in streamwise flow rate variations of Figure 9(a) significantly decrease in the downstream sections of the bf end. On the other hand, in the bf region neither the lubricant type nor the used numerical method play a notable role in the results; thus the velocity profiles are very close especially when compared with the downstream section profiles. Furthermore as lubricant film gets narrower $(x \geq 0.04 \mathrm{~m})$, isotropic profiles become distant whereas iterative approach show similar curves which can be verified by the $3.4 \%$ and $0.8 \%$ apart mean flow rate values of the isotropic and iterative methods for SAE 30 and SAE 70, respectively.

Pressure variations, given in Figure 10(a), of both methods are similar to those defined by Nabhan et al. [5], Kumar et al. [9], and Shigley [13]. It is found that all the variations can be fitted by sixth order polynomials $\left(P(x)=\sum_{j=0}^{6} c_{j} x^{j}\right)$, with less than $0.08 \%$ error, but the deviations within the methods become more apparent with viscous lubricants; such as the peak values $\left(\mathrm{P}_{\max }\right)$ of the methods are apart by 4.81-18.2-42.4\% for SAE 30-50-70, respectively. Moreover, the maximum pressure locations, which is the primary concern of the system damage foresight, are closer to the bearing exit in the isotropic cases, involving higher shifts from the accurate with more viscous fluids. In addition, the end of back flow region can be predicted by locating the onset of $\frac{\mathrm{d}^{2} \mathrm{P}}{\mathrm{dx}^{2}}<0$ in Figure 10(a), especially using the streamwise pressure variation of the iterative method, with a precision better than $0.06 \%$.

Temperature dependency of the lubricant viscosity put the impress on the temperature distribution by making it the main concern of the iterative method. The augmentation curves of Figure 10(b) imply that, for the determination of temperature rise, isotropic approach can safely be used in the case of a low viscosity oil (SAE 30), which is in harmony with the findings of Hargreaves and Elgezawy [3]. On the other hand, the exit plane temperature values of the isotropic and iterative methods are $3.87^{\circ} \mathrm{C}$ apart, which corresponds to $51.8 \%$ higher streamwise increase in the isotropic case, for SAE 70 flow. Moreover towards the exit plane, in the narrower sections of the flow volume, the increasing trends of temperature become steeper for all of the lubricants in either of the methods. This can be explained by the higher local lubricant velocities, neighbouring the lower solid boundary, than the lower surface speed in the region of $x>0.0455 \mathrm{~m}$, where the longitudinal velocity 


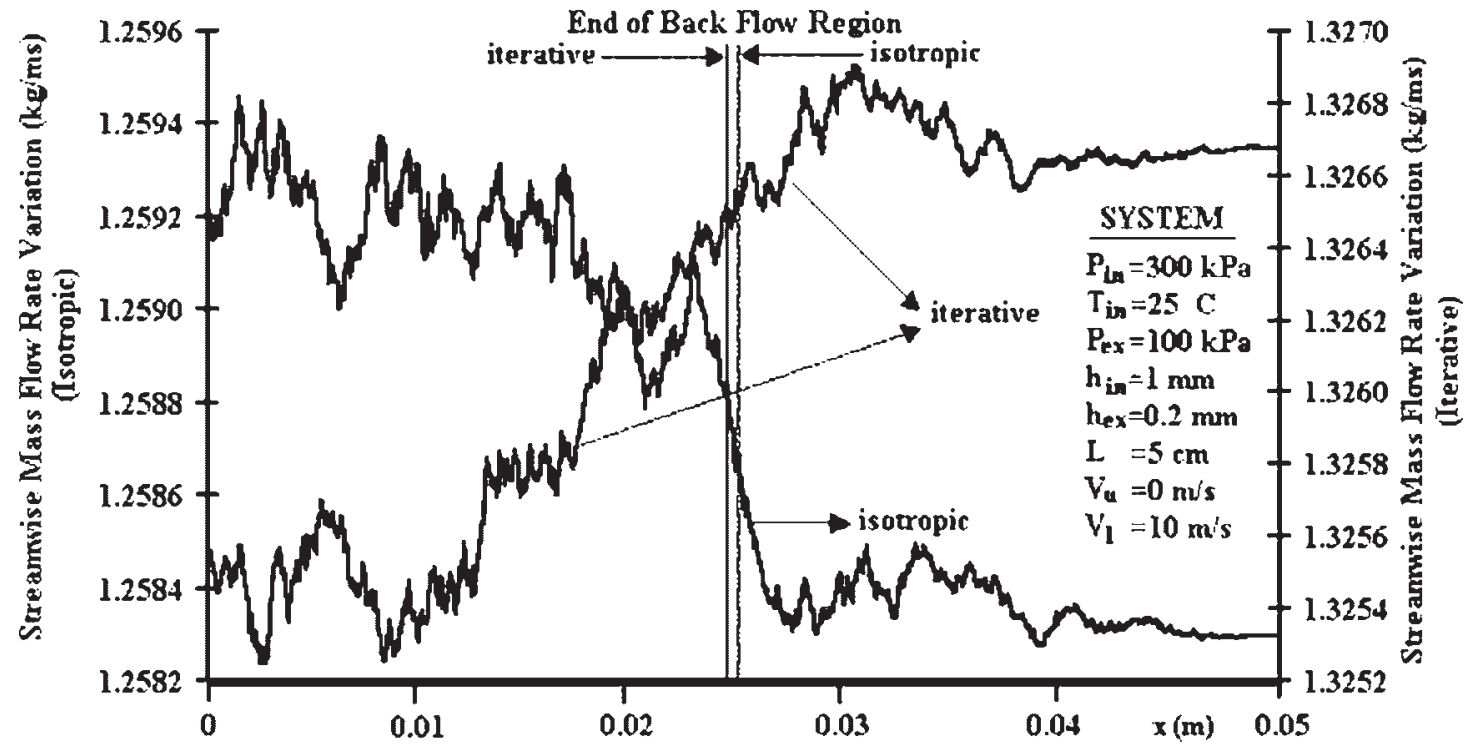

(a)

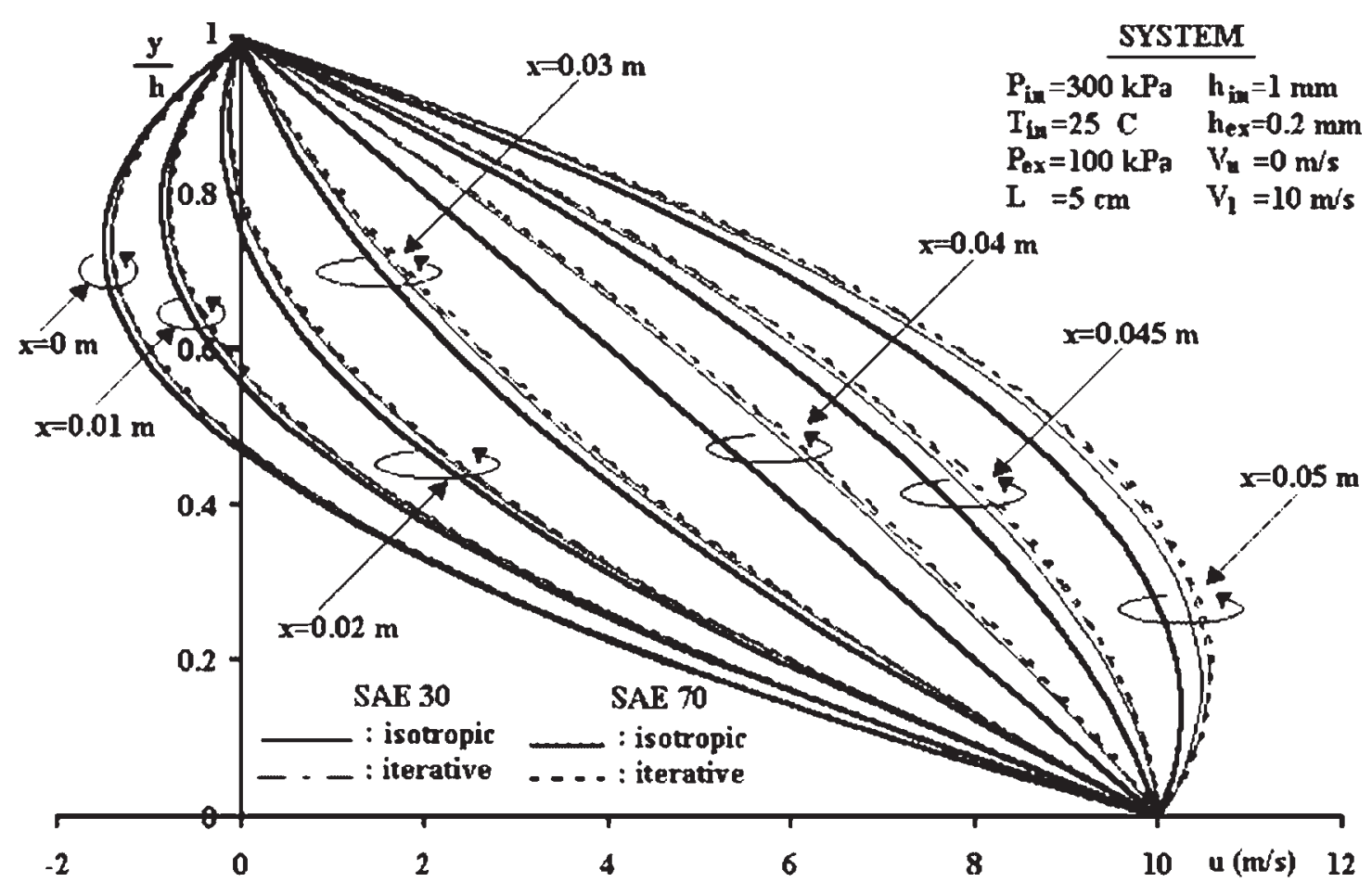

(b)

Figure 9 Comparison of isotropic and iterative methods by lubricant (a) mass flow rate and (b) longitudinal (y-) velocity profiles.

gradient on the lower bearing surface is positive $\left(\frac{\mathrm{du}}{\mathrm{dy}}{ }_{\mathrm{y}=0}>0\right)$. The onset of the augmented temperature slopes, thus the positive velocity gradients, are also shown in Figure 10(b).
For the bearing with $\mathrm{h}_{\mathrm{in}}=1 \mathrm{~mm}, \mathrm{~h}_{\mathrm{ex}}=0.2 \mathrm{~mm}$, and $\mathrm{L}=5 \mathrm{~cm}$, the primary and nodal results are displayed in Figures 5(b)-(c) for the isotropic and iterative runs, respectively. Although the bearing load 


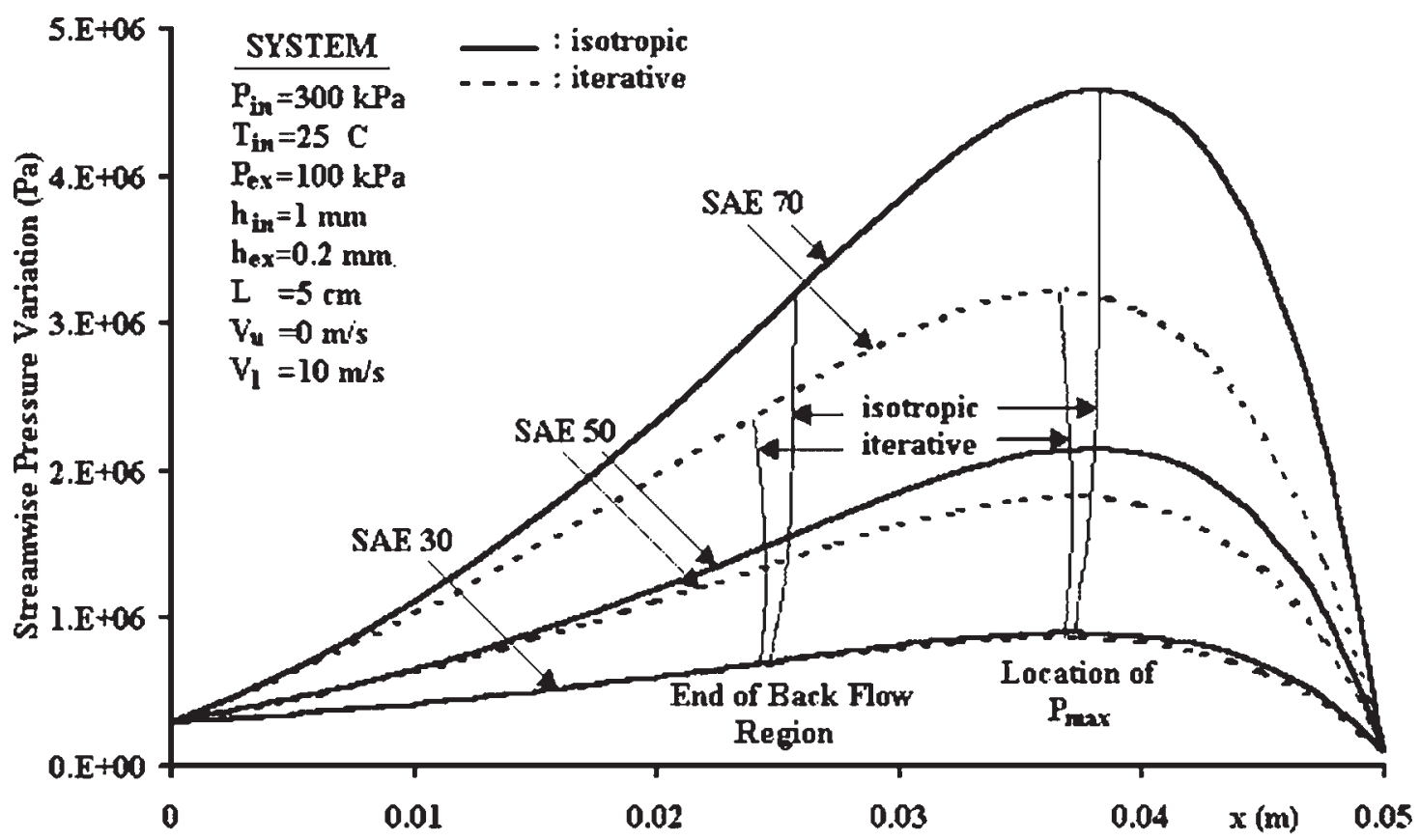

(a)

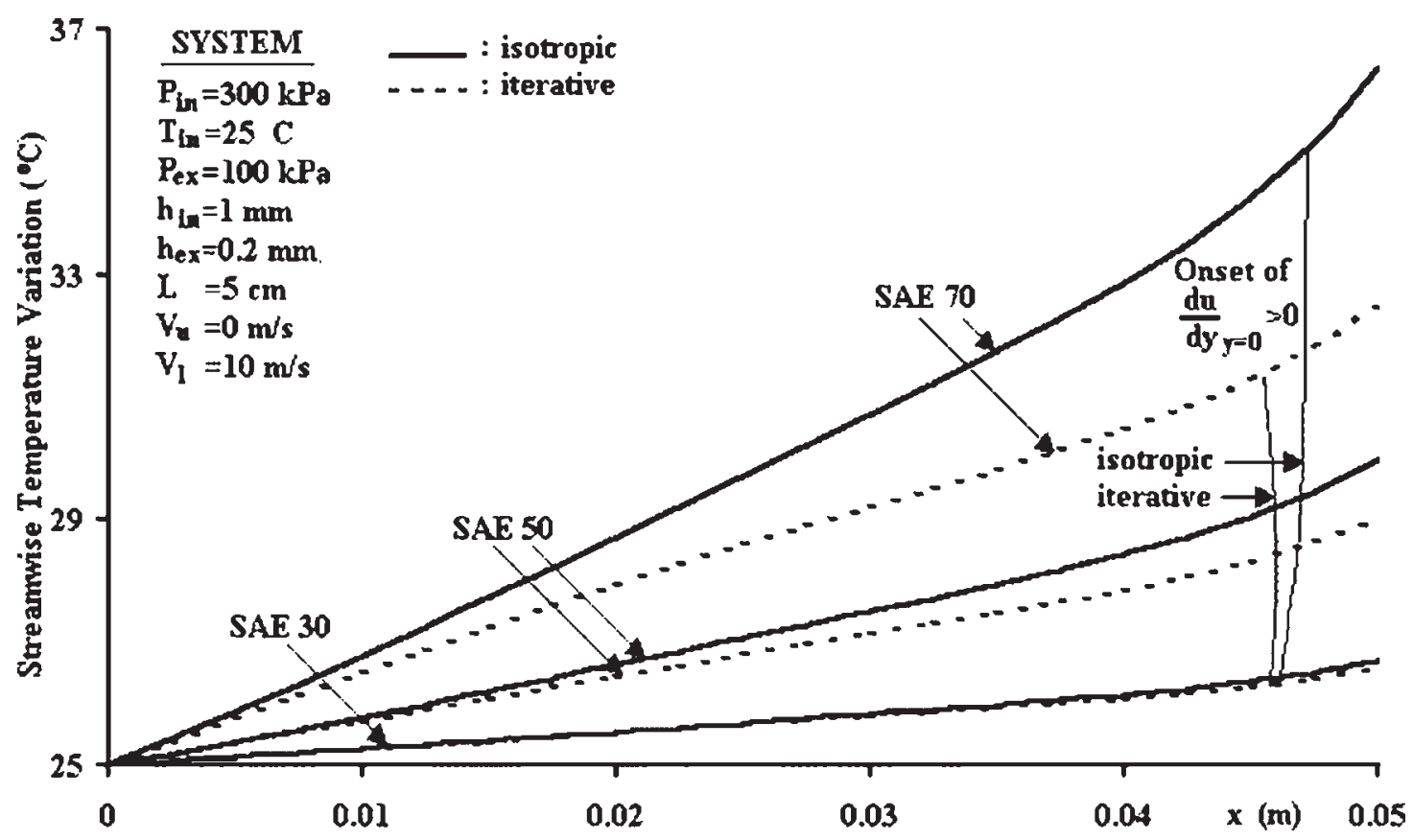

(b)

Figure 10 Comparison of isotropic and iterative methods by lubricant (a) pressure and (b) temperature.

value of the isotropic run appears to be better than that of the iterative, power loss and temperature increase results turn out to be undesirable due to the higher-constant viscosity throughout the flow volume.
The nodal comparisons are totally in harmony with the above discussions of Figures 9 and 10. Especially the viscosity $(\mu)$ values, at the mid-location $(\mathrm{x}=2.5 \mathrm{~cm})$ of the bearing, put forward the notable 
role of temperature on lubricant viscosity with a decay rate of $29.2 \%$ (1.484806-1.051918 Pas), which show parallelism with the records of Fang et al. [8].

The deviations between the isotropic and iterative approaches for different flow geometries are discussed through the 3D carpet diagrams of Figures 11(a)-(b) for the friction force and for the load carrying capacity, respectively. For a bearing with $\mathrm{L}=5 \mathrm{~cm}$ and $\mathrm{h}_{\mathrm{in}} / \mathrm{h}_{\mathrm{ex}}=5$, isotropic load values are higher than the iterative by $3.8 \%$ and $32.3 \%$ for SAE 30 and SAE 70 , respectively, and the corresponding rates for the friction force are $7.4 \%$ and $45.1 \%$. Application of the methods to a longer bearing with a narrower exit $\left(\mathrm{L}=10 \mathrm{~cm}\right.$ and $\left.\mathrm{h}_{\mathrm{in}} / \mathrm{h}_{\mathrm{ex}}=10\right)$ constitute higher deviations both in the load values by $32.8 \%$ and $170.4 \%$ (Fig. 11(b)) and in the friction force values by $40.2 \%$ and 201.2\% (Fig. 11(a)) for SAE 30 and SAE 70 type lubricants, respectively. Figure 11 further put forward that the isotropic approach, especially with more viscous lubricants (SAE 70), result in a steeper trend for long-narrow bearings. Whereas the iterative method, thus the temperature dependency, mild the increase character in either design consideration, similar to the reports of Kumar et al. [9], and show nearly a constant friction force for bearings with $L \geq 4$ $\mathrm{cm}$ and $\mathrm{h}_{\mathrm{in}} / \mathrm{h}_{\mathrm{ex}} \geq 5$.

Table 1 verifies the above discussion by interpreting the deviations of the two approaches with two different lubricants at two different inlet temperatures from the point of load, friction force, temperature rise, maximum pressure, power loss, and pumping power. For all cases, the differences are augmented by longer bearing geometries with higher $\mathrm{h}_{\mathrm{in}} / \mathrm{h}_{\mathrm{ex}}$ ratios, whereas using a more viscous lubricant with the same inlet temperature resulted up to 5.8 times more shifted values. On the other hand, when the inlet temperature of SAE 70 is increased to $75^{\circ} \mathrm{C}$, which causes a decrease in the inlet viscosity by 25.45 times, at the upper geometric boundary of the theoretical model $\left(\mathrm{L}=10 \mathrm{~cm}\right.$ and $\left.\mathrm{h}_{\mathrm{in}} / \mathrm{h}_{\mathrm{ex}}=10\right)$, the errors are in the range of $1.16 \%$ to $6.92 \%$, which are $9.5-53$ times lower than the deviation rates of the same configuration with an inlet temperature of $25^{\circ} \mathrm{C}$. Moreover,

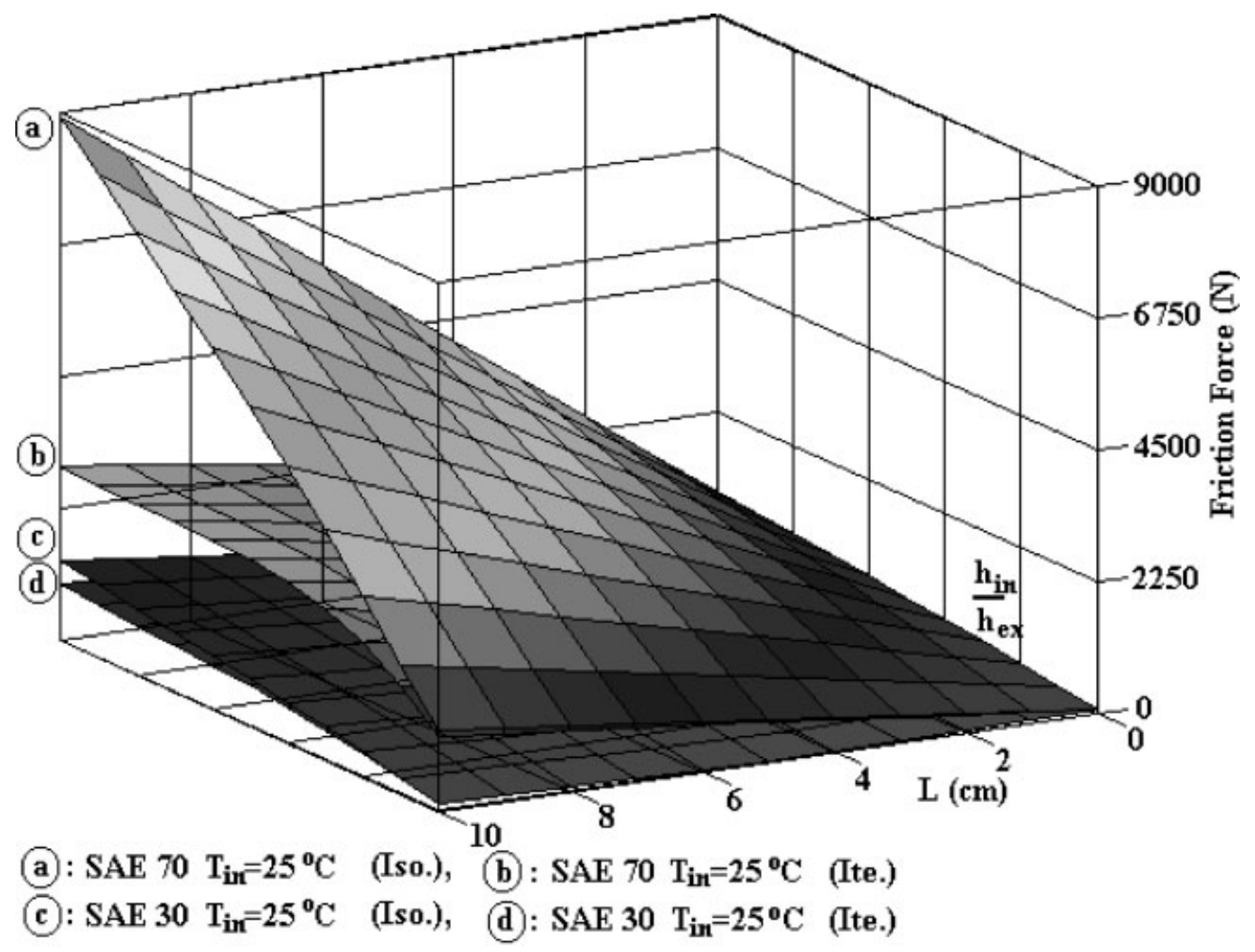

(a)

Figure 11 Comparison of isotropic and iterative methods by (a) friction force and (b) load for different bearing lengths and inlet-exit height ratios. 


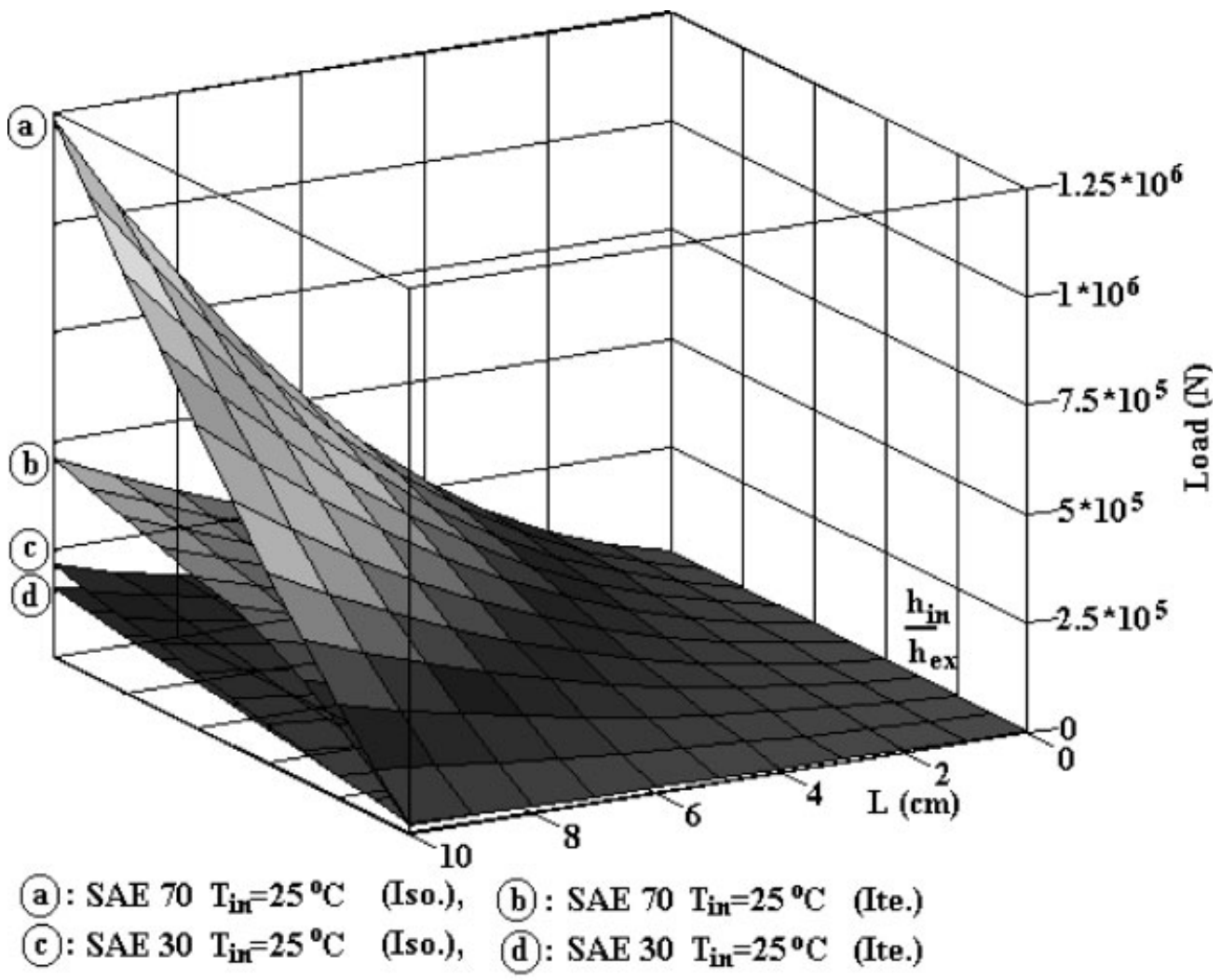

(b)

Figure 11 (Continued)

among the investigated six design considerations of slider bearings, the isotropic approach deviates from the iterative the least for the pumping power case and the most in the temperature rise calculations.

\section{CONCLUSIONS}

The program "HYDRO-LUB" makes it easy to study the viscous thermo-hydrodynamic character of plane slider-bearing lubrication. It covers all important aspects of geometric design, thermodynamic inputs, boundary conditions, and the temperature dependency of lubricant viscosity. The easy to use menu-driven structure of the program, together with the enhanced graphical capabilities, allows students and engineers to easily explore the effect of changing design parameters on the overall performance of real time systems.

The comparisons of the isotropic and iterative methods, through the demonstrated project by "HYDRO-LUB," bring up the following determinations not only for the mechanical engineering students but also for the researchers dealing with hydrodynamic lubrication:

- The deviations are more evident with longernarrower bearings, thus the compulsion in the use of the iterative method is more apparent.

- If the calculation time is of high concern, isotropic method can be used in the applications with thinner lubricants at high inlet temperatures.

- Comparative discussions on the results of the isotropic and iterative methods showed that the errors in the isotropic approach get higher with more viscous lubricants at low inlet temperatures.

- All the design considerations get higher values in the isotropic method than that of the iterative, but it is only mass flow rate that increases with the application of the iterative approach.

- Isotropic method shifts the end of back flow region and maximum pressure location towards downstream.

- Towards the exit, the slope of the temperature variation increases instantly which can be explained by the positive longitudinal gradient 
Table 1 Percent Deviation of the Isotropic and Iterative Methods

\begin{tabular}{|c|c|c|c|c|c|c|c|c|c|}
\hline \multirow[b]{2}{*}{ Lubricant type } & \multirow[b]{2}{*}{$\mathrm{T}_{\text {in }}\left({ }^{\circ} \mathrm{C}\right)$} & \multirow[b]{2}{*}{$\mathrm{L}(\mathrm{cm})$} & \multirow[b]{2}{*}{$\mathrm{h}_{\text {in }} / \mathrm{h}_{\mathrm{ex}}$} & \multicolumn{6}{|c|}{$\%$ Deviation } \\
\hline & & & & W & $\mathrm{F}_{\mathrm{f}}$ & $\Delta \mathrm{T}$ & $\mathrm{P}_{\max }$ & $\boldsymbol{\Omega}_{\mathrm{lo}}$ & $\boldsymbol{\Omega}_{\mathrm{p}}$ \\
\hline \multirow{9}{*}{ SAE 30} & \multirow{9}{*}{25} & \multirow{3}{*}{1} & 1 & 0.10 & 0.11 & 0.13 & 0.00 & 0.29 & 0.43 \\
\hline & & & 5 & 0.28 & 1.95 & 1.41 & 0.40 & 1.47 & 0.07 \\
\hline & & & 10 & 1.63 & 5.01 & 5.39 & 2.97 & 1.87 & 3.33 \\
\hline & & \multirow{3}{*}{5} & 1 & 0.08 & 5.00 & 0.01 & 0.00 & 0.11 & 0.10 \\
\hline & & & 5 & 3.23 & 7.15 & 7.73 & 4.81 & 6.78 & 0.88 \\
\hline & & & 10 & 14.14 & 21.98 & 25.07 & 20.86 & 21.18 & 3.11 \\
\hline & & \multirow{3}{*}{10} & 1 & 0.24 & 2.04 & 1.01 & 0.00 & 0.81 & 0.20 \\
\hline & & & 5 & 7.93 & 13.63 & 15.27 & 11.08 & 13.18 & 1.82 \\
\hline & & & 10 & 29.40 & 40.20 & 46.11 & 41.27 & 39.46 & 4.55 \\
\hline \multirow{9}{*}{ SAE 70} & \multirow{9}{*}{25} & \multirow{3}{*}{1} & 1 & 0.14 & 2.80 & 0.81 & 0.00 & 0.63 & 0.17 \\
\hline & & & 5 & 5.43 & 10.85 & 11.96 & 7.87 & 9.91 & 1.83 \\
\hline & & & 10 & 22.00 & 32.52 & 37.22 & 31.89 & 31.98 & 3.81 \\
\hline & & \multirow{3}{*}{5} & 1 & 0.75 & 5.22 & 4.56 & 0.00 & 4.35 & 0.20 \\
\hline & & & 5 & 32.30 & 45.11 & 51.90 & 42.36 & 44.30 & 5.00 \\
\hline & & & 10 & 97.81 & 119.83 & 140.12 & 133.98 & 119.01 & 8.79 \\
\hline & & \multirow{3}{*}{10} & 1 & 1.38 & 9.64 & 9.16 & 0.00 & 8.95 & 0.19 \\
\hline & & & 5 & 59.67 & 78.48 & 91.51 & 77.09 & 77.56 & 7.28 \\
\hline & & & 10 & 170.42 & 201.10 & 237.12 & 233.84 & 199.79 & 11.07 \\
\hline \multirow{9}{*}{ SAE 70} & \multirow{9}{*}{75} & \multirow{4}{*}{1} & 1 & 0.03 & 0.01 & 0.00 & 0.00 & 0.01 & 0.01 \\
\hline & & & 5 & 0.03 & 0.38 & 0.05 & 0.02 & 1.69 & 1.63 \\
\hline & & & 10 & 0.09 & 0.99 & 0.80 & 0.14 & 5.03 & 4.20 \\
\hline & & & 1 & 0.05 & 0.07 & 0.00 & 0.00 & 0.21 & 0.21 \\
\hline & & \multirow[t]{3}{*}{5} & 5 & 0.22 & 1.19 & 0.90 & 0.33 & 1.47 & 0.56 \\
\hline & & & 10 & 1.19 & 3.21 & 3.50 & 2.10 & 3.63 & 0.12 \\
\hline & & & 1 & 0.05 & 0.24 & 0.00 & 0.00 & 0.18 & 0.18 \\
\hline & & \multirow[t]{2}{*}{10} & 5 & 0.58 & 1.95 & 1.93 & 0.92 & 2.15 & 0.21 \\
\hline & & & 10 & 3.21 & 6.17 & 6.92 & 5.12 & 5.68 & 1.16 \\
\hline
\end{tabular}

of flow velocity profiles near the lower solid boundary, being a consequence of the narrowing of the flow volume.

\section{REFERENCES}

[1] A. A. Ozalp, A computer assisted approach to industrial gas turbine performance calculation, Comput Appl Eng Educ 7 (3) (1999), 171-179.

[2] S. Sanz, M. F. Iskander, and L. Yu, Development of an interactive multimedia module on antenna theory and design, Comput Appl Eng Educ 8 (1) (2000), 11-17.

[3] D. J. Hargreaves, and A. S. Elgezawy, A new model for combined Couette and Poiseuille flows in the transverse groove of a plane inclined slider bearing, Tribology Int 31 (6) (1998), 297-303.

[4] N. C. Das, A study of optimum load capacity of slider bearings lubricated with power law fluids, Tribology Int 32 (1999), 435-441.

[5] M. B. W. Nabhan, G. A. Ibrahim, and M. Z. Anabtawi, Analysis of hydrodynamic journal bearings lubricated with a binary water-based lubricant, Wear 209 (1997), 13-20.
[6] J. R. Lin, Optimal design of one-dimensional porous slider bearings using the Brinkman model, Tribology Int 34 (2001), 57-64.

[7] E. Hoglund, Influence of lubricant properties on elastohydrodynamic lubrication, Wear 232 (1999), 176184.

[8] N. Fang, L. Chang, M. N. Webster, and A. Jackson, A non-averaging method of determining the rheological properties of traction fluids, Tribology Int 33 (2000), $751-760$.

[9] B. V. R. Kumar, P. S. Rao, and P. Sinha, A numerical study of performance of a slider bearing with heat conduction to the pad, Finite Elements Analysis Des 37 (2001), 533-547.

[10] R. K. Pandey and M. K. Ghosh, A thermal analysis of traction in elastohydrodynamic rolling/sliding line contacts, Wear 216 (1998), 106-114.

[11] M. K. Ghosh and K. Gupta, Thermal effect in hydrodynamic lubrication of line contacts-piezoviscous effect neglected, Int J Mech Sci 40 (6) (1998), 603-616.

[12] J. G. Yoo and K. W. Kim, Numerical analysis of grease thermal elastohydrodynamic lubrication problems using the Herschel-Bulkley model, Tribology Int 30 (6) (1997), 401-408. 
[13] J. E. Shigley, Mechanical Engineering Design. McGraw-Hill, Singapore, 1986.

[14] A. Cameron, Basic Lubrication Theory. Prentice Hall, UK, 1981.

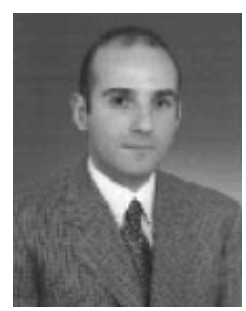

A. Alper Ozalp graduated from the Mechanical Engineering Department of Middle East Technical University (METU) in Ankara-Turkey in 1994 with honors and also received his MSc from the same university in 1996. During his research assistant years in METU, he not only contributed certain projects on design and test of ventilation fans, oil pumps, and valves but also involved in the control group of the emergency fans of Ankara-Underground system. Dr. Ozalp got his $\mathrm{PhD}$ degree in 2001 from the Mechanical Engineering Department of Uludag University in Bursa-Turkey, where he is currently an assistant professor. His research interests include experimental fluid mechanics and heat transfer applications on curved surfaces with pressure gradients and engineering software development especially for undergraduate level education. He teaches courses on Fluid Mechanics, Hydraulic-Pneumatic Systems, and Measurement Techniques and Analysis. Dr. Ozalp has several published journal and symposium papers and he is also a member of International WHO'S WHO of Professionals and New York Academy of Sciences.
[15] M. S. Burgess, Advanced Visual Basic. AddisonWesley Longman Higher Education, UK, 1994.

[16] S. C. Chapra and R. P. Canale, Numerical Methods for Engineers. McGraw-Hill, Singapore, 1990.

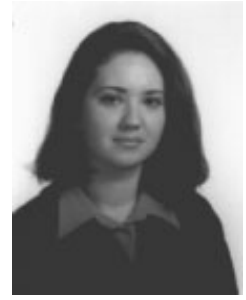

S. Ayse Ozel graduated from the Computer Engineering and Information Sciences Department of Bilkent University in Ankara-Turkey in 1996 with honors. She received her MSc degree from Industrial Engineering Department of Uludag University in Bursa. During her MSc research in Uludag University, she studied on scheduling of manufacturing and computer processes, and developed a software system for scheduling jobs in press-lines of a car manufacturing company in Bursa. In 1999, she moved back to Ankara and started her PhD study in Computer Engineering Department of Bilkent University where she is currently a research assistant. Her research interests include XML and web query languages, semantic web, web data management, database management systems, and database management systems based engineering software development. 